\title{
Inhibition of mRNA and Protein Synthesis in the CA1 Region of the Dorsal Hippocampus Blocks Reinstallment of an Extinguished Conditioned Fear Response
}

\author{
Martín Cammarota, ${ }^{1,2}$ Lia R. M. Bevilaqua, ${ }^{1}$ Daniel Kerr, ${ }^{1}$ Jorge H. Medina, ${ }^{2}$ and Iván Izquierdo ${ }^{1}$ \\ ${ }^{1}$ Memorial Center, Department of Biochemistry, Instituto de Ciências Biológicas e da Saúde, Federal University of Río Grande do Sul, Porto Alegre 90035- \\ 003, RS, Brazil, and 2Neuroreceptor Laboratory, Institute of Cellular Biology and Neurosciences, Faculty of Medicine, University of Buenos Aires, Buenos \\ Aires 1121, Argentina
}

\begin{abstract}
Memories are extinguished by the repeated presentation of a conditioned stimulus in the absence of an unconditioned stimulus to which it has been associated. It is believed that extinction establishes a new hierarchy of responses rather than an actual forgetting of the original response, which can usually reappear spontaneously after interruption of the extinction process. In this study, our aim was to analyze how profound extinction can be. Rats were trained in a one-trial, step-down inhibitory avoidance paradigm and then were exposed to several extinction sessions in which they were allowed to freely explore the apparatus for $30 \mathrm{sec}$ after having stepped down. Extinction was complete enough so that there was no spontaneous recovery, and test session performance could not be enhanced by pharmacological agents with well known facilitative actions on retrieval. After being submitted to a new training session, control animals reacquired the avoidance response; however, animals failed to do so after receiving bilateral intra-CA1 infusions of either the protein synthesis inhibitor anisomycin or the mRNA synthesis blocker 5,6-dichloro-1- $\beta$-d-ribofuranosyl benzimidazole 15 min before the retraining session. Our results indicate that extinction can be carried to a point at which reinstallment of the conditioned response requires, like the original learning, de novo gene expression and protein synthesis in the CA1 region of the dorsal hippocampus.
\end{abstract}

Key words: memory; learning; extinction; reinstallment, hippocampus; protein synthesis; gene expression

\section{Introduction}

Repeated memory retrieval without reinforcement leads to extinction of memories (Pavlov, 1956). Like original learning, extinction involves acquisition of new information (Corcoran and Maren, 2001), which superimposes, but does not destroy, the original learned association (Rescorla, 2001). In fact, extinction is believed to result from a change in the hierarchy of learned responses, by which the newly acquired behavior replaces the original conditioned response (CR) as an animal's first choice (Rescorla, 2001). This differentiates extinction from forgetting, which consists, rather, of the actual loss of memories (McGaugh, 1971).

In one-trial inhibitory avoidance (IA), a fear-motivated learning task (Gold, 1986), rats associate a conditioned stimulus (CS; an elevated platform present in a given context) with an unconditioned stimulus (US; a shock given to the foot when they step down from that platform). The CR is to refrain from stepping down. If animals are tested without a shock, they extinguish that response (Vianna et al., 2001); that is, the CS-no shock associa-

\footnotetext{
Received Aug. 19, 2002; revised Nov. 7, 2002; accepted Nov. 13, 2002.

This work was supported by grants from Conselho Nacional de Desenvolvimento Cientifico e Tecnológico, Companha de Aperfeiçoamento de Pessoal de Nível Superior, Fundação de Amparo a Pesquisa do Estado do Rio Grande (Brazil), and Consejo Nacional de Investigaciones Científicas y Técnicas (Argentina).

Correspondence should be addressed to Dr. Iván Izquierdo, Centro de Memória, Instituto de Ciências Biológicas e da Saúde, Departamento Bioquímica, Universidade Federal do Rio Grande do Sul, Ramiro Barcellos 2600, Anexo, Porto Alegre 90035-003, RS, Brazil. E-mail: izquier@terra.com.br.

Copyright $\odot 2003$ Society for Neuroscience $\quad 0270-6474 / 03 / 230737-05 \$ 15.00 / 0$
}

tion predominates over the previously learned CS-US association, and with repeated testing, the animals stay on the platform less and less time.

NMDA receptors, calcium-calmodulin-dependent protein kinase II, PKA, mitogen-activated protein kinase (MAPK), and protein synthesis are required in the rat hippocampus for extinction of IA (Vianna et al., 2001; Szapiro et al., 2003). These requirements are similar but not identical to those of the consolidation of the original learning (Izquierdo and McGaugh, 2000; Müller-Igaz et al., 2002). Extinction of conditioned taste aversion in rats, which depends on the insular cortex rather than on the hippocampus, requires protein synthesis in that cortex (Berman and Dudai, 2001), whereas extinction of fear-motivated startle behavior requires NMDA receptors (Falls et al., 1992; Walker et al., 2002) and MAPK activity in the amygdala but not in the hippocampus (Lu et al., 2001).

Training rats to relearn extinguished tasks is usually easier than training them to learn the original task; fewer trials are required to attain criterion (Izquierdo et al., 1965), it may result in greater strength of the original learning (Rescorla, 2001), and it can be obtained through exposure to the US alone (Anokhin et al., 2002). Indeed, if extinction is interrupted for $\geq 1 \mathrm{~d}$, the extinguished response usually recovers spontaneously (Santini et al., 2001).

Can extinction be made so complete that there is no spontaneous recovery and that reacquisition of the original task again 
requires gene expression and protein synthesis? Conceivably, strengthening the unconditioned component of extinction should enhance extinction, because the weight of the new CS-no shock association on retrieval should increase at the expense of the former CS-US association. Here we describe experiments showing precisely this for IA. Rats were allowed to remain in the apparatus for $30 \mathrm{sec}$ after they stepped down from the platform in test sessions. This had several effects indicative of enhanced extinction: spontaneous recovery was not observed; retrieval of the original task after extinction was not recovered by well known retrieval enhancers; and importantly, relearning the original task required gene expression and protein synthesis, as if the animals had to learn that task anew.

\section{Materials and Methods}

Surgery and intrahippocampal infusions. Three-month-old male Wistar rats (220-250 gm) were used. The animals were raised in our own facilities, had ad libitum access to food and water, were housed three to five to a cage, and were kept at $22^{\circ} \mathrm{C}$ in a $12 \mathrm{hr}$ light/dark cycle (lights on at 7:00 A.M.). Depending on the experiment, animals were or were not implanted with cannulas into the hippocampus. To implant the cannulas, rats were deeply anesthetized with thiopental $(30-50 \mathrm{mg} / \mathrm{kg}$, i.p.), and 27 gauge cannulas were stereotaxically aimed $1.0 \mathrm{~mm}$ above the stratum pyramidale of the dorsal CA1 region of the hippocampus [coordinates: anterior, -4.3 ; lateral, \pm 4.3 ; ventral, 2.6 , in accordance with the description by Paxinos and Watson (1986)]. To deliver the various drugs, we used a 30 gauge infusion cannula connected by a polyethylene tube to a 1 $\mu \mathrm{l}$ microsyringe. Infusions were performed over $30 \mathrm{sec}$, first on the left side and then on the right side; the infusion cannula was kept in place for an additional $1 \mathrm{~min}$ to minimize backflow of the injectant. Placement of infusion cannulas was verified postmortem by standard histological procedures (Bevilaqua et al., 1997; Müller-Igaz et al., 2002), and was correct (i.e., within the pyramidal cell layer of CA1) in $95 \%$ of the implanted animals. Only data from animals with correct cannula implants were analyzed. Animals were allowed to recover from surgery for $4 \mathrm{~d}$ before submitting them to behavioral tests.

Behavioral procedures. Rats were subjected to one-trial, step-down IA as described previously (Bevilaqua et al., 1997; Izquierdo et al., 1997; Barros et al., 2000, 2001). The training apparatus was a $50 \times 25 \times 25 \mathrm{~cm}$ white acrylic box, the floor of which was a series of 1-mm-caliber bronze bars spaced $1 \mathrm{~cm}$ apart. The left end of the floor was covered by a $7-\mathrm{cm}-$ wide, $2.5-\mathrm{cm}$-high wood platform. Animals were gently placed on the platform facing the left rear corner (CS). When they stepped down onto the grid and had placed their four paws on it, they received a $2 \mathrm{sec}, 0.5 \mathrm{~mA}$ scrambled shock to the foot (US), and were then immediately removed from the training box and placed in their home cages. The long-term memory associated with the learning of this task persisted for at least $31 \mathrm{~d}$ after the training session (Izquierdo et al., 2000). Rats were tested for retention several times after training, with an interval of $24 \mathrm{hr}$ between sessions (see below). A ceiling of $180 \mathrm{sec}$ was imposed on retention test measures. In the test sessions, the animals were left to freely explore the apparatus for $30 \mathrm{sec}$ after they had stepped down. During this period, they stepped up onto the platform and down again several times. All experiments and surgical procedures were conducted according to $\mathrm{Na}$ tional Institutes of Health guidelines for animal care.

Drugs. 5,6-dichloro-1- $\beta$-d-ribofuranosyl benzimidazole (DRB) was obtained from Calbiochem (San Diego, CA). Anisomycin, Sp-cAMPs, 2,3,4,5tetrahydro-7,8-dihydroxy-1-phenyl-1H-3-benzazepine (SKF38393), and oxotremorine were purchased from Research Biochemicals (Natick, MA). Adrenocorticotropin $_{1-24}$ (ACTH) was supplied by ICN Pharmaceuticals (Costa Mesa, CA). DRB was dissolved in dimethylsulfoxide (DMSO; final concentration $0.1 \%$ in saline), whereas all other drugs were dissolved in saline.

Statistics. Because of the ceiling of $180 \mathrm{sec}$ imposed on test session measures, data are expressed as medians (interquartile ranges) and were analyzed by the two-tailed Mann-Whitney $U$ test or the Kruskal-Wallis test followed by Dunn's post hoc comparisons, when appropriate.

\section{Results}

\section{Extinction with no spontaneous recovery}

To extinguish the learned IA response, rats were tested without reinforcement during 5 consecutive days (first test at $24 \mathrm{hr}$ after training). During each extinction session the animals were left to freely explore the training box for $30 \mathrm{sec}$ after they stepped down onto the grid. Retention test performance declined over the five extinction sessions, down to a point at which step-down latency was not statistically different from that observed during the training session (Fig. 1). Moreover, no spontaneous recovery of the original avoidance response was detected when the animals were tested again $8 \mathrm{~d}$ after the extinction protocol was interrupted (Fig. 1 ), suggesting that the protocol had produced an enhanced extinction.

\section{Well known retrieval enhancers did not improve test session performance after extinction}

How complete had the extinction of the aversive response been? To answer the question, we studied the effect that drugs with facilitative action on the expression of the avoidance memory had on retrieval of the extinguished response. We reasoned that if the original memory trace was still available, then treatments that were able to enhance its recall could overcome the effect of the extinction procedure. The results of these experiments are summarized in Figure 2. Trained animals were submitted to four extinction sessions (TT1-TT4) and, 15 min before the fifth test (TT5), they received bilateral $0.5 \mu \mathrm{l}$ intra-CA1 infusions of the stimulant of PKA, Sp-cAMPs $(0.5 \mu \mathrm{g} /$ side $)$, the dopamine $\mathrm{D}_{1^{-}}$ receptor agonist SKF38393 $(2.5 \mu \mathrm{g} /$ side $)$, the muscarinic agonist oxotremorine $(0.3 \mu \mathrm{g} / \mathrm{side})$ (Barros et al., 2000, 2001), or $\mathrm{ACTH}_{1-24}(0.25 \mu \mathrm{g} / \mathrm{kg}$, i.p.) (Izquierdo et al., 2002). In contrast to what happened in unextinguished animals (Fig. $2 B$ ), none of these treatments increased retention test performance on TT5 (Fig. 2A)

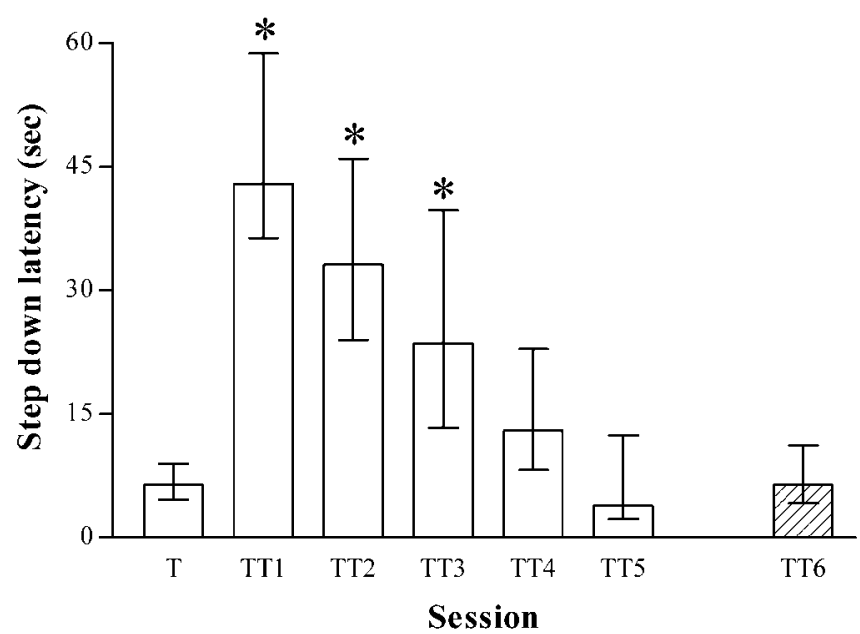

Figure 1. Unimplanted animals $(n=27)$ were trained $(T)$ to perform a one-trial, step-down IA task and were tested for 5 consecutive days (TT1-TT5; first test $24 \mathrm{hr}$ after training). During test sessions, animals were allowed to freely explore the training box for $30 \mathrm{sec}$ after they stepped down from the platform. To evaluate the spontaneous recovery of the avoidance response, animals were tested once again $8 \mathrm{~d}$ after the fifth extinction session (TT6). Data are depicted as median \pm interquartile range of the step-down latency (i.e., the time animals spend on the platform before stepping down to the grid). ${ }^{*} p<0.01$ versus training session latency in Dunn's post hoc comparison after Kruskal-Wallis test. 

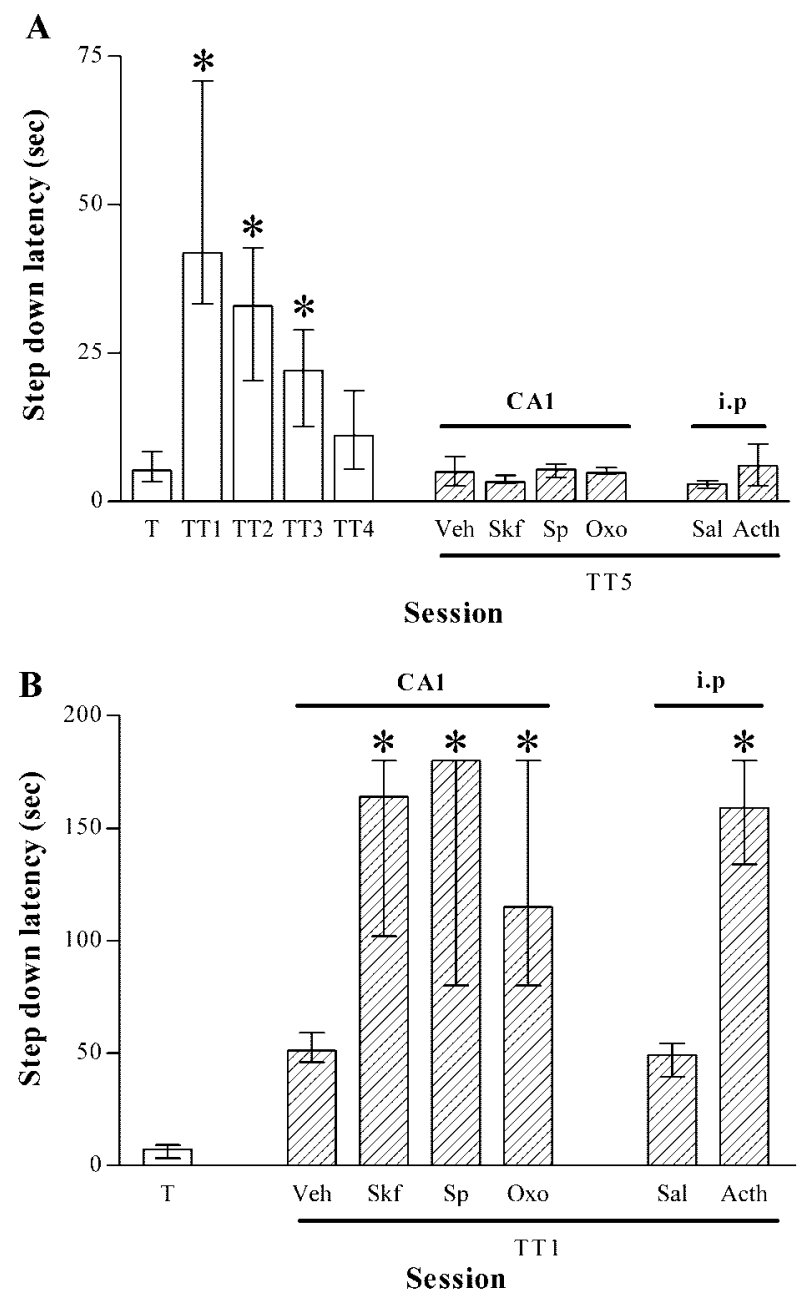

Figure 2. A, Animals bilaterally implanted with cannulas aimed to the CA1 region of the dorsal hippocampus $(n=40)$ were trained to perform a one-trial step-down IA task and were tested without reinforcement for 5 consecutive days (TT1-TT5; first test $24 \mathrm{hr}$ after training). Fifteen minutes before $\mathrm{TT} 5$, they received bilateral intra-CA 1 infusions of either saline (Veh; $n=$ 7), Sp-cAMPs (Sp; $0.5 \mu \mathrm{g} / \mathrm{side} ; n=6$ ), SKF38393 (Skf; $2.5 \mu \mathrm{g} / \mathrm{side} ; n=6$ ), or oxotremorine (0xo; $0.3 \mu \mathrm{g} /$ side; $n=7$ ), or an intraperitoneal administration of saline (Sal; $n=7$ ) or $\mathrm{ACTH}_{1-24}($ Acth; $0.25 \mu \mathrm{g} / \mathrm{kg} ; n=7)$. Bars represent median \pm interquartile range of the step-down latency. ${ }^{*} p<0.05$ versus training $(T)$ session latency in Dunn's post hoc comparison after the Kruskal-Wallis test. $B$, Animals bilaterally implanted with cannulas aimed to the CA1 region of the dorsal hippocampus ( $n=42)$ were trained as in $A$, and, 15 min before a test session performed $24 \mathrm{hr}$ after training (TT1), they received bilateral infusions of either saline (Veh; $n=7$ ), Sp-cAMPs (Sp; $0.5 \mu \mathrm{g} / \mathrm{side} ; n=7$ ), SKF38393 (Skf; $2.5 \mu \mathrm{g} / \mathrm{side} ; n=7$ ), or oxotremorine $(0 \times 0 ; 0.3 \mu \mathrm{g} / \mathrm{side} ; n=7)$, or an intraperitoneal administration of saline ( $(\mathrm{al} ;, n=$ 7) or $\mathrm{ACTH}_{1-24}(A c t h ; 0.25 \mu \mathrm{g} / \mathrm{kg} ; n=7)$. Data are presented as median \pm interquartile range of the step-down latency. ${ }^{*} p<0.05$ versus Veh or Sal group latencies at TT1 in a MannWhitney two-tailed test.

\section{Relearning after extinction requires gene expression and protein synthesis}

To analyze whether gene expression and new protein synthesis are required to reinstall the extinguished IA response, animals were trained and submitted to five daily extinction sessions as explained above. At TT5, instead of allowing the animals to freely explore the training box, they received a shock to the foot, similar to the one they had received immediately after stepping down from the platform during the original training. Fifteen minutes before TT5 the animals received bilateral intrahippocampal infusions of anisomycin $(0.8 \mu \mathrm{l} ; 80 \mu \mathrm{g} / \mathrm{side})$, DRB $(0.8 \mu \mathrm{l} / \mathrm{side} ; 100$ $\mu \mathrm{M})$, or the proper vehicle. One day after this retraining session,

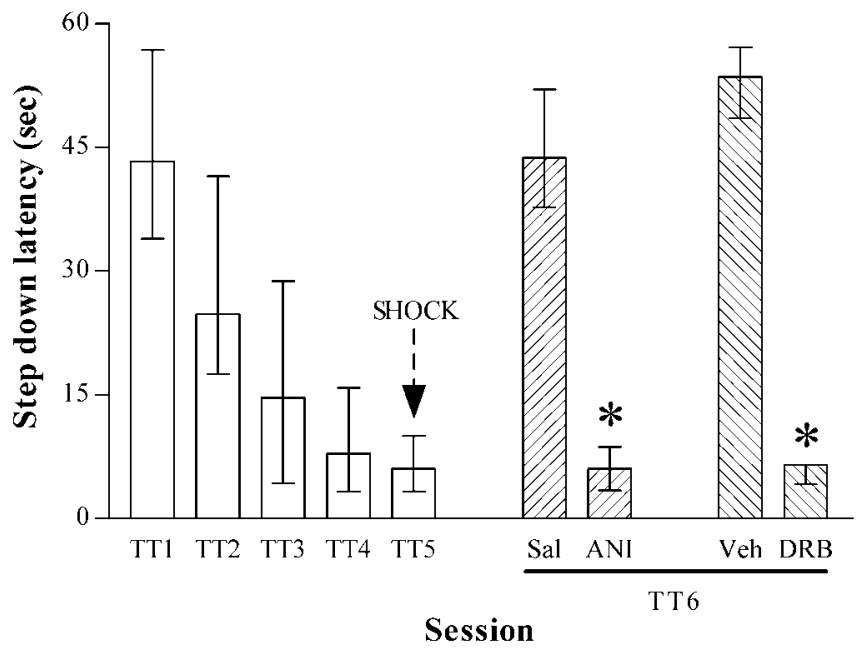

Figure 3. Rats bilaterally implanted with cannulas aimed to the CA1 region of the dorsal hippocampus $(n=45)$ were trained into a one-trial, step-down IA task and tested for 4 consecutive days (TT1-TT4; first test $24 \mathrm{hr}$ after training). After that, the animals were randomly assigned to four different groups. Fifteen minutes before the fifth test session (TT5), each experimental group received bilateral intra-CA1 infusions of saline ( $\mathrm{Sal} ; n=12)$, anisomycin ( $A N I ; 80 \mu \mathrm{g} / \mathrm{side} ; n=12), 0.1 \%$ DMSO in saline (Veh; $n=12)$, or DRB (100 $\mu \mathrm{m} ; n=9)$. During this session, instead of being allowed to freely explore the training box, rats received a scrambled electric shock to the foot equal to that received in the training session $(0.5 \mathrm{~mA}, 2 \mathrm{sec})$ immediately after they stepped down to the grid. Retention was measured in a subsequent test session performed $24 \mathrm{hr}$ later (TT6). ${ }^{*} p<0.001$ versus Veh or Sal groups at TT6 in a MannWhitney two-tailed test.

animals were tested once more (TT6). In control animals, retention levels returned to TT1 levels; conversely, in animals treated with DRB or anisomycin, retention scores remained as low as they had been at TT5 (Fig. 3); that is, retraining was unable to reinstall the original memory.

To evaluate whether the observed requirement of gene expression and protein synthesis to recover retention test performance was a consequence of extinction or was instead the result of a deleterious effect of anisomycin and DRB on retrieval or performance, animals were trained and tested twice at $24 \mathrm{hr}$ intervals between tests. The first test was followed by a shock to the foot immediately after the animals stepped down from the platform. Animals received intrahippocampal infusions of anisomycin, $\mathrm{DRB}$, or vehicle $15 \mathrm{~min}$ before TT1. The retraining procedure led to a much greater retention test performance on TT2 regardless of whether the animals were retrained with saline, $0.1 \% \mathrm{DMSO}$ in saline, anisomycin, or DRB. Similar results were obtained when the first test session was performed $24 \mathrm{hr}(1 \mathrm{~d})$ or $120 \mathrm{hr}$ ( $5 \mathrm{~d}$ ) after training (Fig. 4, $A, B$, respectively). Therefore, retraining without an intervening series of extinction tests led to greater retention test performance, regardless of the number of days between training and the first test session, and this enhancement did not require gene expression or protein synthesis in the hippocampus.

\section{Discussion}

Our results indicate that allowing the animals to remain in the apparatus after they stepped down strengthens the value of the CS-no US association relative to that of the original CS-US association. This resulted in an extinction after which (1) there was no spontaneous recovery within $8 \mathrm{~d}$, (2) retention test performance could not be enhanced by treatments known well to facilitate retrieval of this learning task (intrahippocampal SKF38393, Sp-cAMPs and oxotremorine, and intraperitoneal ACTH) (Izquierdo et al., 1997; Barros et al., 2000, 2001), and (3) retraining 
A

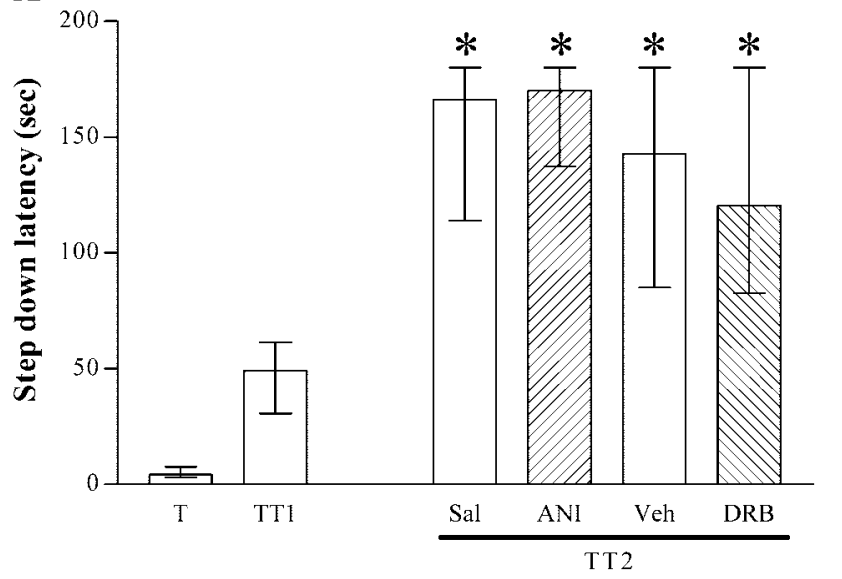

Session

B

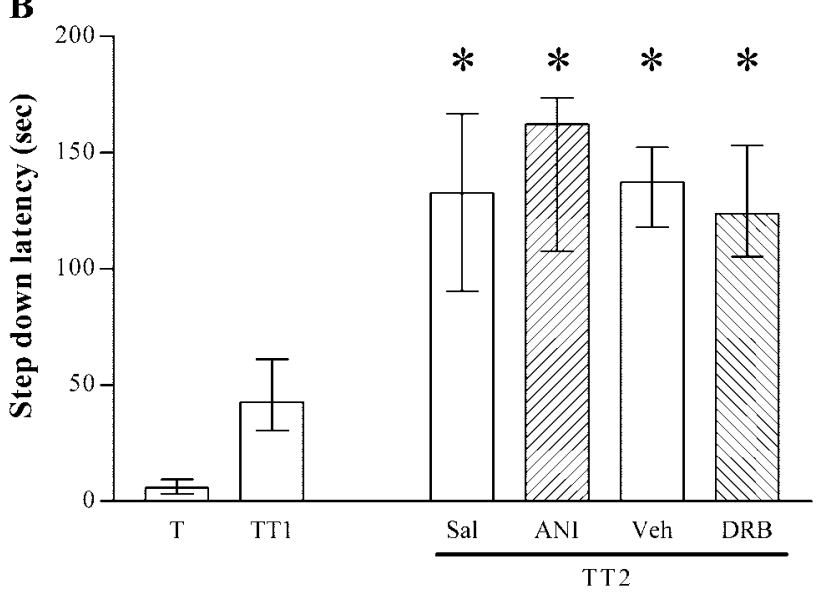

Session

Figure 4. A, Animals bilaterally implanted with cannulas aimed to the CA1 region of the dorsal hippocampus $(n=34)$ were trained into a one-trial step-down IA task and tested (TT1) $24 \mathrm{hr}$ later. During this test session, immediately after rats stepped down onto the grid they received a scrambled electric shock to the foot equal to the shock they received in the training session $(0.5 \mathrm{~mA}, 2 \mathrm{sec})$. Fifteen minutes before TT1, the animals were bilaterally infused into the CA1 region with either saline $(S a l ; n=8)$, anisomycin ( $A N / ; 80 \mu \mathrm{g} / \mathrm{side} ; n=9), 0.1 \%$ DMSO in saline (Veh; $n=8)$, or DRB (100 $\mu$ m; $n=9)$. Retention was measured in a subsequent test session (TT2) performed $24 \mathrm{hr}$ later (i.e., $48 \mathrm{hr}$ after training). B, Animals bilaterally implanted with cannulas aimed at the CA1 region of the dorsal hippocampus $(n=32)$ were treated as in $A$ except that TT1 and TT2 were performed 120 and $144 \mathrm{hr}$ after training, respectively. ${ }^{*} p<0.05$ versus TT1 in a Mann-Whitney two-tailed test.

in the original task required both gene expression and protein synthesis, as are needed for the original learning (Müller-Igaz et al., 2002) and for its extinction (Vianna et al., 2001, 2003).

However, it is impossible to determine whether, despite appearances, extinction as described here reflected an effective uninstallment of the original memory. The genes that needed to be activated to obtain relearning might well be different from those that must be activated for the original learning of this task (Müller-Igaz et al., 2002) or indeed for its extinction (Vianna et al., 2001). Likewise, the synapses involved in the original training, extinction, and retraining could well be different from each other (Medina et al., 2002). There is abundant evidence indicating that extinction does not result from forgetting or full erasure of the original learning (Rescorla, 1979, 2001). For example, in the present study, there may have been remnants of the original task after the extinction, but clearly, those remnants were insufficient to sustain a full capacity for reinstallment of that task.

The question of how strong extinction can be is important from a practical point of view. Extinction has been used for more than 70 years in the treatment of phobias (Walker and Davis, 2002) and more recently as a basis of "exposure," "desensitization," or "flooding" techniques for the treatment of panic and post-traumatic stress disorders (Beckett, 2002; Rothbaum and Schwartz, 2002), either alone or coupled with anxiolytic treatments (Van Minnen et al., 2002). Clearly, any method that strengthens the unconditioned aspect of the CS-no US association is preferable to those that merely repeat the original experience or the CS alone. The mere exposure to information on the traumatic event without due emphasis on the absence of the US may lead only to a revival of the experience and the subsequent intensification of suffering (Beckett, 2002; Walker et al., 2002).

\section{References}

Anokhin KV, Tiunova AA, Rose SP (2002) Reminder effects-reconsolidation or retrieval deficit? Pharmacological dissection with protein synthesis inhibitors following reminder for a passive-avoidance task in young chicks. Eur J Neurosci 15:1759-1765.

Barros DM, Izquierdo LA, Mello e Souza T, Ardenghi PG, Pereira P, Medina JH, Izquierdo I (2000) Molecular signalling pathways in the cerebral cortex are required for retrieval of one-trial avoidance learning in rats. Behav Brain Res 114:183-192.

Barros DM, Mello e Souza T, De David T, Choi H, Aguzzoli A, Madche C, Ardenghi P, Medina JH, Izquierdo I (2001) Simultaneous modulation of retrieval by dopaminergic $D_{1}, \beta$-noradrenergic, serotonergic- $1 \mathrm{~A}$ and cholinergic muscarinic receptors in cortical structures of the rat. Behav Brain Res 124:1-7.

Beckett WS (2002) Post-traumatic stress disorder. N Engl J Med 346:1495-1498.

Berman DE, Dudai Y (2001) Memory extinction, learning anew, and learning the new: dissociations in the molecular machinery of learning in cortex. Science 291:2417-2419.

Bevilaqua L, Ardenghi P, Schroder N, Bromberg E, Schmitz PK, Schaeffer E, Quevedo J, Bianchin M, Walz R, Medina JH, Izquierdo I (1997) Drugs acting upon the cyclic adenosine monophosphate/protein kinase A signalling pathway modulate memory consolidation when given late after training into rat hippocampus but not amygdala. Behav Pharmacol 8:331-338.

Corcoran KA, Maren S (2001) Hippocampal inactivation disrupts contextual retrieval of fear memory after extinction. J Neurosci 21:1720-1726.

Falls WA, Miserendino MJ, Davis M (1992) Extinction of fear-potentiated startle: blockade by infusion of an NMDA antagonist into the amygdala. J Neurosci 12:854-863.

Gold PE (1986) The use of avoidance training in studies of modulation of memory storage. Behav Neural Biol 46:87-98.

Izquierdo I, McGaugh JL (2000) Behavioural pharmacology and its contribution to the molecular basis of memory consolidation. Behav Pharmacol 11:517-534.

Izquierdo I, Wyrwicka W, Sierra G, Segundo JP (1965) Établissement de reflexes conditionnés de trace pendant le sommeil naturel chez le chat. Actual Neurophysiol 6:277-296.

Izquierdo LA, Schröder N, Ardenghi P, Quevedo J, Bevilaqua LRM, Netto CA, Izquierdo I, Medina JH (1997) Systemic administration of ACTH or vasopressin in rats reverses the amnestic effect of posttraining $\beta$-endorphin but not that of intrahippocampal infusion of protein kinase inhibitors. Neurobiol Learn Mem 68:197-202.

Izquierdo LA, Barros DM, Medina JH, Izquierdo I (2000) Novelty enhances retrieval of one trial avoidance learning in rats 1 or 31 days after training unless the hippocampus is inactivated by different receptor antagonists and enzyme inhibitors. Behav Brain Res 117:215-220.

Izquierdo LA, Barros DM, Medina JH, Izquierdo I (2002) Stress hormones enhance retrieval of fear conditioning acquired either one day or many months before. Behav Pharmacol 13:203-213.

Lu KT, Walker DL, Davis M (2001) Mitogen-activated protein kinase cascade in the basolateral nucleus of the amygdala is involved in extinction of fear-potentiated startle. J Neurosci 21:RC162(1-5). 
McGaugh JL (1971) Memory. In: Psychology (Harlow H, McGaugh JL, Thompson RF, eds), pp 310-343. San Francisco: Albion.

Medina JF, Repa JC, Mauk MD, LeDoux JE (2002) Parallels between cerebellum- and amygdala-dependent conditioning. Nat Rev Neurosci 3:122-131.

Müller-Igaz L, Vianna MRM, Medina JH, Izquierdo I (2002) Two time periods of hippocampal mRNA synthesis are required for memory consolidation of fear-motivated learning. J Neurosci 22:6781-6789.

Pavlov IP (1956) Conditioned reflexes. New York: Dover.

Paxinos G, Watson C (1986) The rat brain in stereotaxic coordinates. San Diego: Academic.

Rescorla RA (1979) Aspects of the reinforcer learned in second-order Pavlovian conditioning. J Exp Psychol Anim Behav Process 5:79-95.

Rescorla RA (2001) Retraining of extinguished Pavlovian stimuli. J Exp Psychol Anim Behav Process 27:115-124.

Rothbaum BO, Schwartz AC (2002) Exposure therapy for posttraumatic stress disorder. Am J Psychother 56:59-75.

Santini E, Müller RU, Quirk GJ (2001) Consolidation of extinction learning involves transfer from NMDA-independent to NMDA-dependent memory. J Neurosci 21:9009-9017.
Szapiro G, Vianna MRM, McGaugh JL, Medina JH, Izquierdo I (2003) The role of NMDA glutamate receptors, PKA, MAPK and CAMKII in the hippocampus in extinction of conditioned fear. Hippocampus 13:53-58.

Van Minnen A, Wessel I, Dijkstra T, Roelofs K (2002) Changes in PTSD patients' narratives during prolonged exposure therapy: a replication and extension. J Trauma Stress 15:255-258.

Vianna MR, Szapiro G, McGaugh JL, Medina JH, Izquierdo I (2001) Retrieval of memory for fear-motivated training initiates extinction requiring protein synthesis in the rat hippocampus. Proc Natl Acad Sci USA 98:12251-12254.

Vianna MRM, Müller-Igaz L, Coitinho A, Medina JH, Izquierdo I (2003) Memory extinction requires gene expression in rat hippocampus. Neurobiol Learn Mem 79:51-56.

Walker DL, Davis M (2002) The role of amygdala glutamate receptors in fear learning, potentiated startle, and extinction. Pharmacol Biochem Behav 71:379-372.

Walker DL, Ressler KJ, Lu KT, Davis M (2002) Facilitation of conditioned fear extinction by systemic administration or intra-amygdala infusions of D-cycloserine assessed with fear-potentiated startle in rats. J Neurosci 22:2343-2351. 